\title{
Antenatal depression and its predictors in Lahore, Pakistan
}

\author{
A. Humayun, I.I. Haider, ${ }^{2}$ N. Imran, ${ }^{3}$ H. Iqbal ${ }^{4}$ and N. Humayun ${ }^{5}$
}

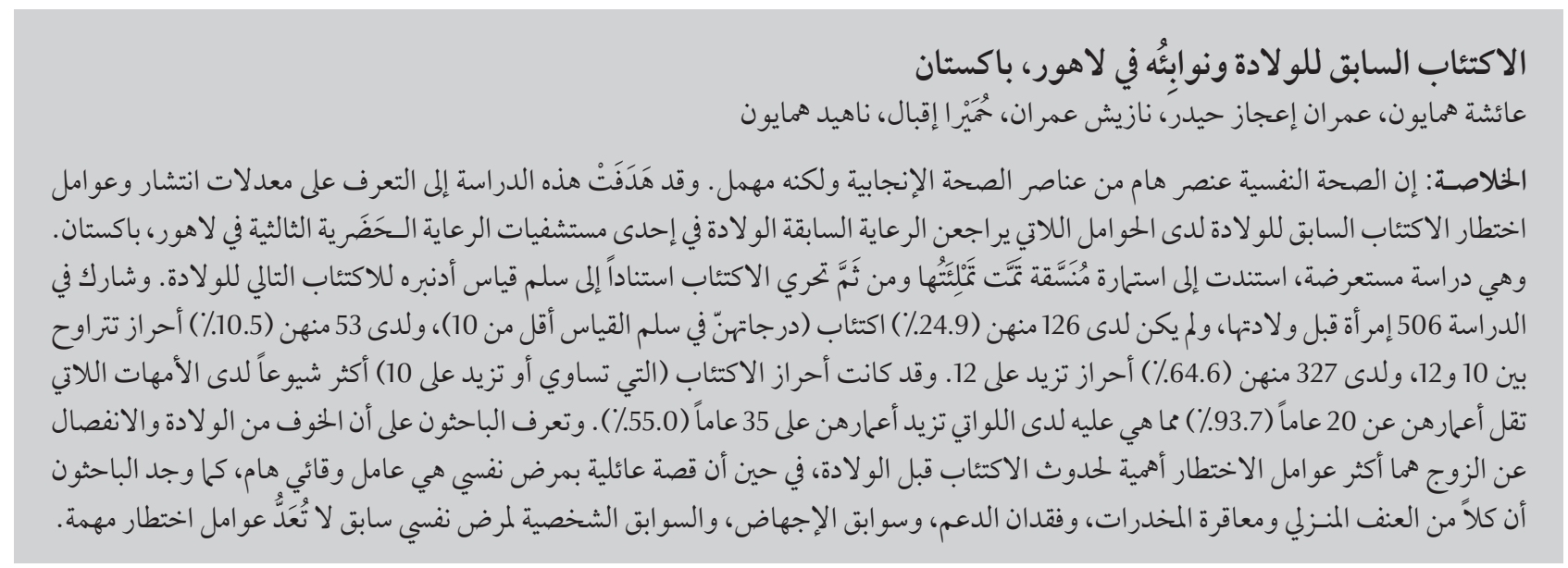

ABSTRACT Mental health is an important but neglected component of reproductive health. This study aimed to determine the prevalence and risk factors for antenatal depression among women attending for antenatal care at an urban tertiary care hospital in Lahore, Pakistan. In a cross-sectional study, structured questionnaires were filled and screening for depression was done using the Edinburgh postnatal depression scale (EPDS). Out of 506 antenatal attendees 126 (24.9\%) had no depression (EPDS scores < 10), 53 (10.5\%) scored 10-12 and 327 (64.6\%) had EPDS scores $>12$. Depression scores $(\geq 10)$ were more common in mothers aged $<20$ years $(93.7 \%)$ than those aged $>35$ years $(55.0 \%)$. Fear of childbirth and separation from husband were identified as significant risk factors for development of antenatal depression, while family history of psychiatric illness was significant protective factor. Domestic violence, drug abuse, lack of support, previous miscarriage and personal history of previous psychiatric illness were not found to be significant risk factors.

\section{Dépression prénatale et facteurs prédictifs à Lahore (Pakistan)}

RÉSUMÉ La santé mentale est une composante importante et pourtant négligée de la santé génésique. La présente étude visait à déterminer la prévalence et les facteurs de risque de la dépression prénatale chez les femmes consultant un service de soins prénatals à l'hôpital de soins de santé tertiaires de la ville de Lahore (Pakistan). Dans une étude transversale, des questionnaires structurés ont été complétés puis analysés à l'aide de l'Edinburgh postnatal depression scale (échelle de dépression post-natale d'Édimbourg) à la recherche d'indications de dépression. Sur les 506 patientes en période prénatale, 126 (24,9\%) ne souffraient pas de dépression (scores < 10), 53 (10,5\%) ont obtenu des résultats entre 10 et 12 et 327 (64,6\%) ont eu des résultats supérieurs à 12 sur l'échelle de dépression post-natale d'Édimbourg. Les scores de dépression $(\geq 10)$ étaient plus fréquents chez les femmes âgées de moins de 20 ans (93,7 \%) que chez celles de plus de 35 ans (55,0\%). La peur de l'accouchement et une séparation conjugale ont été identifiées comme des facteurs de risque significatifs pour le développement de la dépression prénatale, alors que les antécédents familiaux de maladie psychiatrique étaient des facteurs de risque protecteurs importants. La violence domestique, la toxicomanie, l'absence de soutien et des antécédents de fausses-couches et de maladie psychiatrique chez la patiente n'ont pas été identifiés comme des facteurs de risque importants.

'Department of Community Medicine, Federal Postgraduate Medical Institute and Shaikh Khalifa Bin Zayed Al-Nahyan Medical College, Lahore, Pakistan (Correspondence to A. Humayun: drayeshah@gmail.com). ${ }^{2}$ Department of Psychiatry and Behavioural Sciences; ${ }^{4}$ Department of Community Health Sciences, Fatima Memorial Hospital College of Medicine and Dentistry, Lahore, Pakistan. ${ }^{3}$ Department of Psychiatry, King Edward Medical University, Lahore, Pakistan. ${ }^{5}$ Department of Community Medicine, Akhtar Saeed Medical and Dental College, Lahore, Pakistan. Received: 18/12/11; accepted: 06/03/12 


\section{Introduction}

Mental health is an important but neglected component of reproductive health. About $10 \%-15 \%$ of women in industrialized countries and between $20 \%-40 \%$ of women in developing countries experience depression during pregnancy or after childbirth. The effects of depression, anxiety and demoralization are amplified in the context of social adversity and poverty [1]. Symptoms of antenatal depression include sadness during most of the day, hopelessness, lack of interest and fatigue, trouble sleeping and eating along with extreme irritability and inability to feel happiness or enjoy. Moreover, inability to feel happy about the pregnancy adds to the confusion and guilt in the affected women. Antenatal depression can have clinical implications such as increased uterine irritability, pregnancy-induced hypertension, pre-eclampsia, postpartum bleeding, decreased uterine artery blood flow and preterm delivery. Common consequences also include emotional and behavioural problems and cognitive delay in children of depressed mothers [2].

Widely ranging rates of depression during pregnancy have been found: for example from $27 \%$ to $62 \%$ [3-5]. A comparison between Pakistani and Canadian women showed a higher proportion of Pakistani women (48.4\%) with antenatal depression than aboriginal (31.2\%) and Cauca$\operatorname{sian}(8.6 \%)$ Canadian women [6]. Risks for depression or anxiety during pregnancy are similar to the risk factors for any other depressive episode. They include personal or family history of depression, relationship difficulties, stressful life events, history of abuse, lack of social support and family violence $[2,7]$. Previous pregnancy loss, problems with pregnancy, unplanned pregnancy and fear of childbirth have also been identified as risk factors for antenatal depression [8]. A study by two of the authors of the current paper to determine the frequency of probable antenatal depression in pregnant women in Pakistan in the 3rd trimester and to assess the risk factors showed a prevalence of $42.7 \%$ and identified a number of effects on obstetric and neonatal outcomes [9]. Another study from Pakistan reported the prevalence of anxiety and/or depression among pregnant women was only $18 \%$. Husband unemployment, lower household wealth, having 10 or more years of formal education and an unwanted pregnancy along with physical/sexual and verbal abuse were associated with depression and/ or anxiety $[10]$.

The current study aimed to identify the frequency of antenatal depression among women attending for antenatal care at a tertiary care hospital in Lahore and to identify the potential risk factors for antenatal depression.

\section{Methods}

\section{Sample}

The sample size was calculated using an expected prevalence of antenatal depression as $10.7 \%$ [11]. The study population was antenatal attendees in their 3rd trimester. All pregnant women in their 3rd trimester consecutively attending the antenatal clinics at a tertiary care hospital in Lahore over the period May to July 2007 were recruited $(n=$ 506); women in the 1 st and 2 nd trimesters were excluded.

Ethical approval for the study was obtained from the ethical review committee of the FMS Center for Health Research, Lahore. The study was conducted in compliance with the ethical principles for medical research involving human subjects of the Helsinki Declaration [12]. Patient names were not recorded to assure confidentiality. Verbal consent was obtained from all subjects and documented in the presence of a witness.

\section{Data collection}

All women completed the Edinburgh Postnatal Depression Scale (EPDS) [13] and a structured questionnaire that was filled through personal interviews by psychiatry postgraduate students. To identify all those with minor or major depression we used the cut off of EPDS score $\geq 10$, but to obtain the frequency of major depression in antenatal period we also analysed patients having EPDS score $>12$. The questionnaire included information about demographic and other potential risk factors for antenatal depression. These variables included history of previous miscarriages, unplanned pregnancy, fear of childbirth, lack of support, separation from husband, domestic violence, drug abuse, family and personal history of psychiatric disorder as nominal variables.

\section{Analysis}

The data were entered and analysed using SPSS, version 16.. For the statistical analysis, the chi-squared test was applied and the statistical association of different factors with the presence of depression in antenatal attendees was determined.

\section{Results}

The mean age the women was 26.5 [standard deviation (SD) 4.2] years, with a range of 18-40 years. The great majority (93.7\%) were in the age group 20-30 years. The women included in the study had gestation between 26 to 36 weeks.

Out of these 506 antenatal attendees, $126(24.9 \%)$ screened negative for depression (EPDS score < 10), 53 (10.5\%) screened positive for depression at EPDS scores between 10-12 and $327(64.6 \%)$ screened positive at the EPDS cut-off > 12. i.e. a total of 380 (75.1\%) screened positive at the EPDS cut-off $\geq 10$.

In younger mothers aged $<20$ years, depression (EPDS score $\geq 10$ ) 
was much more common (8/9, 93.7\%) than among older mothers aged $>35$ years $(11 / 20,55.0 \%)$. The prevalence of depression scores among the women according to the risk factors measured are shown in Table 1 for depression scores $10-12$ and $\geq 12$.

Table 2 shows the prevalence of depression comparing cut-off scores $<10$ with $\geq 10$. The fear of childbirth and separation from husband were identified as significant risk factors for development of antenatal depression, whereas family history of psychiatric illness was a significant protective factor, Among women who feared childbirth $77.8 \%$ had depression scores compared with $69.8 \%$ among those who did not fear childbirth $(P=0.046)$ and $86.5 \%$ of women who were separated from their husbands had depression scores versus $73.8 \%$ who were not separated $(P=$ 0.044). In contrast, among women who had a family history of psychiatric illness only $58.3 \%$ had depression scores compared with $76.9 \%$ of women with no family history $(P=0.005)$.

Domestic violence, drug abuse, lack of support, previous miscarriage and history of previous psychiatric illness were not found to be significant risk factors for antenatal depression in our study. Although more women with a history of domestic violence had depression scores ( $94.1 \%$ versus $74.4 \%$ ), the numbers of women reporting domestic

\begin{tabular}{|c|c|c|c|c|c|c|c|}
\hline \multirow[t]{3}{*}{ Variable } & \multirow{3}{*}{$\begin{array}{c}\text { Total } \\
\left(\begin{array}{c}n=506) \\
\text { No. }\end{array}\right.\end{array}$} & \multirow{2}{*}{\multicolumn{2}{|c|}{$\begin{array}{l}\text { Screened negative } \\
\text { EPDS score }<10 \\
(n=126)\end{array}$}} & \multicolumn{4}{|c|}{ Screened positive } \\
\hline & & & & \multicolumn{2}{|c|}{$\begin{array}{l}\text { EPDS score 10-12 } \\
\qquad(n=53)\end{array}$} & \multicolumn{2}{|c|}{$\begin{array}{l}\text { EPDS score }>12 \\
\qquad(n=327)\end{array}$} \\
\hline & & No. & $\%$ & No. & $\%$ & No. & $\%$ \\
\hline \multicolumn{8}{|l|}{ Age (years) } \\
\hline$<20$ & 9 & 1 & 11.1 & 0 & 0.0 & 8 & 88.9 \\
\hline $20-35$ & 477 & 116 & 24.3 & 49 & 10.3 & 312 & 65.4 \\
\hline$>35$ & 20 & 9 & 45.0 & 4 & 20.0 & 7 & 35.0 \\
\hline \multicolumn{8}{|l|}{ Pregnancy } \\
\hline Unplanned & 233 & 58 & 24.9 & 27 & 11.6 & 148 & 63.5 \\
\hline Planned & 276 & 68 & 24.6 & 26 & 9.4 & 179 & 64.9 \\
\hline \multicolumn{8}{|c|}{ Fear of childbirth } \\
\hline Yes & 334 & 74 & 22.2 & 40 & 12.0 & 220 & 65.9 \\
\hline No & 172 & 52 & 30.2 & 13 & 7.6 & 107 & 62.2 \\
\hline \multicolumn{8}{|c|}{ Miscarriage or intrauterine death } \\
\hline Yes & 180 & 39 & 21.7 & 22 & 12.2 & 119 & 66.1 \\
\hline No & 326 & 87 & 26.7 & 31 & 9.5 & 208 & 63.8 \\
\hline \multicolumn{8}{|c|}{ Lack of support } \\
\hline Yes & 93 & 22 & 23.7 & 9 & 9.7 & 62 & 66.7 \\
\hline No & 413 & 104 & 25.2 & 44 & 10.7 & 265 & 64.2 \\
\hline \multicolumn{8}{|c|}{ Separation from husband } \\
\hline Yes & 52 & 7 & 13.5 & 10 & 19.2 & 35 & 67.3 \\
\hline No & 454 & 120 & 26.4 & 43 & 9.5 & 292 & 64.3 \\
\hline \multicolumn{8}{|c|}{ Domestic violence } \\
\hline Yes & 17 & 1 & 5.9 & 4 & 23.5 & 12 & 70.6 \\
\hline No & 492 & 125 & 25.4 & 49 & 10.0 & 315 & 64.0 \\
\hline \multicolumn{8}{|l|}{ Drug abuse } \\
\hline Yes & 26 & 4 & 15.4 & 3 & 11.5 & 19 & 73.1 \\
\hline No & 480 & 122 & 25.4 & 50 & 10.4 & 308 & 64.2 \\
\hline \multicolumn{8}{|c|}{ Previous psychiatric illness } \\
\hline Yes & 34 & 6 & 17.6 & 3 & 8.8 & 25 & 73.5 \\
\hline No & 472 & 120 & 25.4 & 50 & 10.6 & 302 & 64.0 \\
\hline \multicolumn{8}{|c|}{ Family history of psychiatric illness } \\
\hline Yes & 48 & 20 & 41.7 & 3 & 6.3 & 25 & 52.1 \\
\hline No & 458 & 106 & 23.1 & 50 & 10.9 & 302 & 65.9 \\
\hline
\end{tabular}


violence (physical or verbal or both type of violence) were very small and this did not reach statistical significance $(P$ $=0.085)$. More women with a personal history of psychiatric illness had depression than those without ( $82.4 \%$ versus $74.6 \%$ ), so too did those with a history of drug abuse compared with those who $\operatorname{did}$ not $(84.6 \%$ versus $74.6 \%)$ but these were also not significant $(P=0.41$ and $P$ $=0.249$ respectively) .

\section{Discussion}

A high prevalence of antenatal depression has previously been found in women in Rawalpindi, Pakistan [14]. In the current study in Lahore, the frequency of 3rd trimester antenatal attendees who screened positive for antenatal depression above the EPDS cut-off score of 10 was $75.1 \%$ and above the cut-off score of 12 was $64.6 \%$, which is high compared with other studies in Pakistan and elsewhere [11,15-18]. In a study by Gorman et al. from 10 sites in 8 countries the overall antenatal point prevalence rate for caseness was $11.8 \%$, the rate for depression was $6.9 \%$, the rate for major depression was 3.5\% and the rate for EPDS score 13+ was 8.7\% [18]. A recent meta-analysis of 21 studies concluded that the mean prevalence of depression across the antenatal period was $10.7 \%$, ranging from $7.4 \%$ in the 1 st trimester to a high of $12.8 \%$ in the 2nd trimester [11].
An interesting finding in our study was the higher rate of depression in younger mothers aged $<20$ years than older mothers, which might be explained by the younger women's lack of experience, immaturity and emotional instability $[19,20]$. In a study in the United States (US) young maternal age was associated with greater risk of antenatal and postpartum depressive symptoms, which were attributed to financial hardship, unwanted pregnancy and lack of a partner [21]. Similar findings were reported in other studies from the United Kingdom and US [22,23]. The mean age of our women was 26.5 years, which is identical to a hospitalbased study of postnatal depression in Pakistan that showed the average age

\begin{tabular}{|c|c|c|c|c|c|c|}
\hline \multirow[t]{2}{*}{ Risk factor } & \multirow{2}{*}{$\begin{array}{l}\text { Total } \\
\text { No. }\end{array}$} & \multicolumn{2}{|c|}{$\begin{array}{c}\text { Screened negative } \\
\text { EPDS score }<10 \\
(n=126)\end{array}$} & \multicolumn{2}{|c|}{$\begin{array}{l}\text { Screened positive } \\
\text { EPDS score } \geq 10 \\
(n=380)\end{array}$} & \multirow[t]{2}{*}{$P$-value } \\
\hline & & No. & $\%$ & No. & $\%$ & \\
\hline \multicolumn{7}{|c|}{ Fear of childbirth } \\
\hline Yes & 334 & 74 & 22.2 & 260 & 77.8 & \multirow{2}{*}{0.046} \\
\hline No & 172 & 52 & 30.2 & 120 & 69.8 & \\
\hline \multicolumn{7}{|c|}{ Miscarriage or intrauterine death } \\
\hline Yes & 180 & 39 & 21.7 & 141 & 78.3 & \multirow{2}{*}{0.21} \\
\hline No & 326 & 87 & 26.7 & 239 & 73.3 & \\
\hline \multicolumn{7}{|c|}{ Lack of support } \\
\hline Yes & 93 & 22 & 23.7 & 71 & 76.3 & \multirow{2}{*}{0.75} \\
\hline No & 413 & 104 & 25.2 & 309 & 74.8 & \\
\hline \multicolumn{7}{|c|}{ Separation from husband } \\
\hline Yes & 52 & 7 & 13.5 & 45 & 86.5 & \multirow{2}{*}{0.044} \\
\hline No & 454 & 119 & 26.2 & 335 & 73.8 & \\
\hline \multicolumn{7}{|c|}{ Domestic violence } \\
\hline Yes & 17 & 1 & 5.9 & 16 & 94.1 & \multirow{2}{*}{0.085} \\
\hline No & 489 & 125 & 25.6 & 364 & 74.4 & \\
\hline \multicolumn{7}{|l|}{ Drug abuse } \\
\hline Yes & 26 & 4 & 15.4 & 22 & 84.6 & \multirow{2}{*}{0.25} \\
\hline No & 480 & 122 & 25.4 & 358 & 74.6 & \\
\hline \multicolumn{7}{|c|}{ Previous psychiatric illness } \\
\hline Yes & 34 & 6 & 17.6 & 28 & 82.4 & \multirow{2}{*}{0.41} \\
\hline No & 472 & 120 & 25.4 & 352 & 74.6 & \\
\hline \multicolumn{7}{|c|}{ Family history of psychiatric illness } \\
\hline Yes & 48 & 20 & 41.7 & 28 & 58.3 & \multirow{2}{*}{0.005} \\
\hline No & 458 & 106 & 23.1 & 352 & 76.9 & \\
\hline
\end{tabular}


of women was 26 years. Women with depression were mostly in their 2 nd or 3 rd confinements (38\%) [24].

Factors found to be statistically associated with a higher risk of depression in our study were fear of childbirth and separation from the husband, while family history of psychiatric illness was protective factor for depression. A fear of childbirth in our culture might be related to the process of delivery, the sex of the baby or poor faith in the care provider. These possibilities needs to be explored in further studies as fears related to childbirth need to be determined in the context of Pakistan. Domestic violence, previous miscarriage and personal history of previous psychiatric illness were not found to be risk factors for antenatal depression in our study. Our findings contrast with a study reporting that the strongest factors associated with depression/ anxiety were physical/sexual and verbal abuse [10]. They also contradict a previous study in Pakistan which found that $72 \%$ of women who were physically abused during pregnancy were anxious/depressed [25]. In the US study, the strongest risk factor for antenatal depressive symptoms was a history of depression $(\mathrm{OR}=4.07)$, and the strongest risk for postpartum depressive symptoms was depressive symptoms during pregnancy $(\mathrm{OR}=$ 6.78) or a history of depression before pregnancy $(\mathrm{OR}=3.82)$ [19]. Another study from Pakistan showed a high frequency of antenatal depression (42.7\%) and reported the risk factors to be problems in the marriage, problems with parents/in-laws, history of domestic violence, past history of psychiatric problems and history of postnatal depression. Among the obstetric risk factors, history of previous miscarriages, stillbirth and complications in previous pregnancies reached statistical significance. Moreover, women with antenatal depression faced more obstetric complications and their babies had significantly lower birth weights and lower mean Apgar scores [9]. The study was conducted in a tertiary care setup, which mainly caters upper lower and lower middle socioeconomic class of patients.

The finding that the association of family history of psychiatric illness was protective, rather than a risk, for antenatal depression suggests a contextspecific situation as the females here had specific cultural, social and economic conditions. A meta-analysis by O'Hara and Swain using 77 studies, showed no association of family history of depression with postpartum depression [26].

One limitation of this study was lack of follow-up of these women into the natal and postnatal period in order to determine neonatal outcomes and possible development of postnatal depression. This was due to financial and logistic constraints of the research. This is, however, an areas for future research. Antenatal depression itself is a predictor of postnatal depression. Findings from a study in Egypt revealed that the prevalence of antepartum depression was $25.3 \%$ and that antepartum depression was significantly linked to postpartum depression and negative attitudes to breastfeeding [27]. In a study in the United Arab Emirates in which women were followed from the second trimester of pregnancy until 4 months postpartum, depression in the 2nd and 3rd trimesters was found to be significantly associated with postnatal depression [28], while a study in the Islamic Republic of Iran showed that antenatal state and trait anxiety at 28 and 38 weeks of gestation were independent risk factors associated with postnatal depression [29].

In the present study, despite the high rate of depression, none of the women had been screened for depression and other psychiatric illnesses during routine antenatal checkups. Therefore none of them were receiving any treatment, which means that these females were at risk of developing postnatal depression. To address the growing epidemic of antenatal depression in Pakistan [6], we need to look into its epidemiological basis in our sociocultural context and then plan preventive and control measures.

\section{Conclusions}

Depression was highly prevalent in hospital antenatal attendees in an urban area of Pakistan. Many of the predictors, such fear of childbirth and separation from husband, are modifiable through awareness and counselling. Mental health should be made an integral part of reproductive health services in Pakistan and there is a need to conduct antenatal screening of women for depression and other psychiatric illness, through close collaboration of psychiatry services with the preventive obstetric services.

\section{References}

1. Mental health aspects of women's reproductive health, a global review of literature. Geneva, World Health Organization/ United Nations Population Fund, 2009.

2. Bonari $L$ et al. Perinatal risks of untreated depression during pregnancy. Canadian Journal of Psychiatry, 2004, 49:726-735.

3. Dalton K. Prospective studies into puerperal depression. British Journal of Psychology, 1971, 118:689-692.
4. Rona RJ et al. Anxiety and depression in mothers related to severe malformation of the heart of the child and foetus. Acta Paediatrica, 1998, 87:201-205.

5. Bowen A, Muhajarine N. Prevalence of antenatal depression in women enrolled in an outreach program in Canada. Journal of Obstetric, Gynecologic, and Neonatal Nursing, 2006, 35:491-498. 
6. Shah SM et al. Prevalence of antenatal depression: comparison between Pakistani and Canadian women. Journal of the Pakistan Medical Association, 2011, 61:242-246.

7. Bacchus L, Mezey G, Bewley S. Domestic violence: prevalence in pregnant women and associations with physical and psychological health. European Journal of Obstetrics, Gynecology, and Reproductive Biology, 2004, 113:6-11.

8. Leigh B, Milgrom J. Risk factors for antenatal depression, postnatal depression and parenting stress. BMC Psychiatry, 2008, $8: 24$.

9. Imran N, Haider II. Screening of antenatal depression in Pakistan: risk factors and effects on obstetric and neonatal outcomes. Asia-Pacific Psychiatry, 2010, 2:26-32.

10. Karmaliani R et al. Prevalence of anxiety, depression and associated factors among pregnant women of Hyderabad, Pakistan. International Journal of Social Psychiatry, 2009, 55:414-424.

11. Dennis CL, Ross LE, Grigoriadis S. Psychosocial and psychological interventions for treating antenatal depression. Cochrane Database of Systematic Reviews, 2007, 3:CD006309.

12. Declaration of Helsinki: ethical principles of research involving human subjects. World Medical Association [online] (http:// www.wma.net/en/30publications/10policies/b3/, accessed 17Januray 2013).

13. Edinburgh Postnatal Depression Scale (http://www.fresno ucsf.edu/pediatrics/downloads/edinburghscale.pdf, accessed 26 February 2013).

14. Rahman A et al. Association between antenatal depression and low birthweight in a developing country. Acta Psychiatrica Scandinavica, 2007, 115:481-486.

15. Niaz S, Izhar N, Bhatti MR. Anxiety and depression in pregnant women presenting in the OPD of a teaching hospital. Pakistan Journal of Medical Sciences, 2004, 20:117-119.

16. Blazer DG et al. The prevalence and distribution of major depression in a national community sample: the National Comorbidity Survey. American Journal of Psychiatry, 1994, 151:979-986.

17. Edwards B et al. Antenatal psychosocial risk factors and depression among women living in socioeconomically disadvantaged suburbs in Adelaide, South Australia. Australian and New Zealand Journal of Psychiatry, 2008, 42:45-50.
18. Gorman LL et al.TCS-PND Group. Adaptation of the structured clinical interview for DSM-IV disorders for assessing depression in women during pregnancy and post-partum across countries and cultures. British Journal of Psychiatry, 2004, 46:s17-s23.

19. Aleem S. Emotional stability among college youth. Journal of the Indian Academy of Applied Psychology, 2005, 31(1-2):100-102.

20. Rich-Edwards JW et al. Sociodemographic predictors of antenatal and postpartum depressive symptoms among women in a medical group practice. Journal of Epidemiology and Community Health, 2006, 60(3):221-227.

21. Rich-Edwards JW et al. Sociodemographic predictors of antenatal and postpartum depressive symptoms among women in a medical group practice. Journal of Epidemiology and Community Health, 2006, 60:221-227.

22. Maskey S. Teenage pregnancy: doubts, uncertainties and psychiatric disturbance. Journal of the Royal Society of Medicine, 1991, 84:723-725.

23. Kessler RC et al. Social consequences of psychiatric disorders, II: Teenage parenthood. American Journal of Psychology, 1997, 154:1405-1411

24. Hamirani MM et al. Frequency of prenatal depression in second and third trimesters of pregnancy in Karachi: a hospital based study. Journal of Liaquat University of Medical and Health Sciences, 2006, Sept.-Dec.:106-109.

25. Fikree FF, Bhatti LI. Domestic violence and health of Pakistani women. International Journal of Gynecology and Obstetrics, 1999, 65:195-201

26. O'Hara MW, Swain AM. Rates and risk of postnatal depression-a meta-analysis. International Review of Psychiatry, 1996, 8:37-54.

27. Abou Nazel MW, Nosseir SA. Antepartum and postpartum def pression and infant feeding pattern: a prospective study. Journal of the Egyptian Public Health Association, 1994, 69:397-424.

28. Hamdan A, Tamim H. Psychosocial risk and protective factors for postpartum depression in the United Arab Emirates. Archives of Women's Mental Health, 2011, 14:125-133.

29. Alipour Z, Lamyian M, Hajizadeh E. Anxiety and fear of childbirth as predictors of postnatal depression in nulliparous women. Women and Birth, 25(3):e37-43. 